seared in a hot pan, after having been cut in pieces about two inches square.

I consider this press a valuable accessory to a nurse's outfit.

A. B. Davis.

\title{
THE QUESTION OF RATES AGAIN
}

Dear Ediror: In the Journal for February there is an article among the "Letters to the Editor," "What Is a Fair Rate of Charge?" und among "Questions and Answers" the same query by I. $H$."

About laundry, I never charge for it at all. I charge twenty-five dollars a week, except in contagious cases, when, of course, prices vary and the laundry is cared for. It always seems to me that the necessity for a trained nurse in the house means also the necessity for extra work of all kinds, regardless of the nurse, and, as our mission is to be a help, I think the laundry done outside and no comments on it is the most helpful way, particularly as I always wear white and try to keep clean. There are occasions in a large household where the laundress is expected to do all the laundry work, including the nurscs'. This, of course, is very much the easiest way.

In regard to the other question, about charges, if the first patient I go to is convalescent when another member of the family falls ill. it seems to me the right thing to take care of both, and if more attention is required than $I$ can give I ask for another nurse. Extra pay will not make more hours in the day, nor more strength. One fanily I have taken care of in a variety of ailments. The mother was delivered, the baby splendid. When the baby was six weeks old the three other children had bronchitis, one after the other. By this time we had a nurse-maid for the new baby. The mother still needed care, as she was frail. I took care of all of them, with the help of the German nursery governess and the nurse-maid. They were not sick enough for another nurse to be called in. I never before heard that we were paid twenty-five dollars for one patient.

Mary R. HUMphrey, R.N.

\section{EXTRA PAY AND IAAUNDRY}

Dear Editor: Once when I received a call for diphtheria it was stated that there would be two patients, and as the family was well to do and the work hard I asked thirty-five dollars a week: twenty-five dollars for the case, five dollars because it was contagious, and five dollars extra for the second patient. The family thought it fair, and willingly paid it. 
At another time, on a long case, I was called upon at different times to nurse seven other members of the family, with grip, tonsillitis, etc. One had a light case of pneumonia, and a history sheet was needed for a week.

When pay day came (the family were abundantly able to pay) nothing was said by either party about the extra seven patients.

Some people think twenty-five dollars a week pays for every minute of the day and night for seven days, and that they are entitied to all a nurse can do in that time.

In our state (lowa), when pupil nurses are sent out, the patient is expected to have the laundry done for the nurse, 1 understand, but public sentiment seems to be that a uurse who gets twenty-five dollars a week is expected to pay for her own laundry, be it done in the. family or sent out. In threc and one-half years I have never had a piece done in a patient's house, and have had the offer just twice.

N. E. B.

\section{WHAT IS 'THE NURSE'S DU'YY WHEN DOC'IOR IS CARELESS?}

Dear EDITOle: What is a nurse's duty when a doctor calls on a scarlet-fever patient and makes no changc of clothing on going in or coming out, and, when a doctor's gown is offered him, says: "It is not necessary"? 'J'his has happened three times, and I have hinted and hinted about it. One doctor brings his modicine-case and unpacks it in the room, and takes his time to putting up the medicines, even staying much longer than necessary, visiting with the patient. $\mathrm{He}$ is the kind who does not love trained nurses to begin with; but even then is it the nurse's duty to let it happen every time he calls? What do other private nurses do? There must be other physicians like these. They seem to be common enough in the country towns.

IowA.

[From the old-fashioned standpoint, a nurse should be silent; but we believe the time will come when a nurse will be expected to report such carelessness to the Board of Health. She is not serving the doctor, but the family, and she should have an obligation to the public.-ED.]

\section{'IHE ADVAN'I'AGE OF THE THREE YEARS' COURSE}

Dear Editor: Upon reading Dr. Bristow's paper in the last number of The American Jodrnal of Nursing, and seeing the editorial call for expression from the rank and file as well as from superintendents, I 